\title{
The "seeded" focus group: a strategy to recruit HIV+ community members into treatment research
}

\author{
J Busza, ${ }^{1}$ B Zaba, ${ }^{2,3}$ M Urassa ${ }^{3}$
}

${ }^{1}$ Centre for Population Studies, London School of Hygiene \&

Tropical Medicine, London, UK;

${ }^{2}$ London School of Hygiene \&

Tropical Medicine, London, UK;

${ }^{3}$ National Institute for Medical

Research, Mwanza, Tanzania

Correspondence to:

Ms J Busza, Centre for

Population Studies, London

School of Hygiene \& Tropical

Medicine, 50 Bedford Square,

London WC1B 3DP, UK:

joanna.busza@Ishtm.ac.uk

Accepted 15 July 2008

Published Online First

6 August 2008

\section{ABSTRACT}

Objective(s): We piloted an innovative community-based recruitment approach to contact known HIV+ individuals for referral to treatment without endangering their confidentiality.

Methods: Nested within an HIV cohort study, operations research to monitor and improve rural uptake of antiretroviral therapy (ART) was conducted alongside the introduction of Tanzania's national treatment programme. We confronted the challenge of recruiting participants without inadvertently disclosing their HIV status to family or other community members. During post-test counselling, nurses compiled a list of HIV+ persons who expressed interest in being contacted when ART became available. Study numbers, but not names, of 12 "seeds" were added to a randomly generated list of residents, matched by age group and sex, and all were invited to participate in focus-group discussions on community perceptions of treatment. After the discussion, the original counsellors met each participant in private, inviting the "seed" for ART referral and offering VCT to others.

Results: Ten "seeds" were successfully located and attended the local focus-group discussion; all subsequently volunteered to undergo clinical tests in advance of receiving antiretroviral therapy. They also agreed to participate in a study of barriers to ART access. The other focus-group members contributed useful information on levels of understanding and support for treatment, and several came forward for HIV testing.

Conclusions: The "seeded" focus group is a very straightforward and easily arranged method of recruiting HIV+ people for research or service delivery within a wider context of engaging with local community perceptions.

Numerous studies have examined strategies to increase research participation by underserved groups. ${ }^{1-3}$ Populations such as ethnic minorities, ${ }^{4}$ disabled people, ${ }^{5}$ older people ${ }^{6}$ and those engaged in marginalised or illegal behaviour, for example drug use, $^{7}$ are often excluded from clinical and social science research as a result of being difficult to reach or sceptical of researchers' motives. In developing country settings, particular misgivings regarding the political agenda behind international research initiatives have been found to limit health research participation; ${ }^{8}$ restrictive gender norms similarly affect women's willingness to volunteer. ${ }^{9}$ Certain research topics can also contribute to the vulnerability of potential study participants and discourage enrolment, and sensitive subjects can appear threatening in the context of an interview when "... they are of a deeply personal nature; they impinge on the interests of those being studied; they involve deviance or social control, or they enter the world of that which is personally sacred." ${ }^{10}$ Diseases frequently marked by stigma including cancer, mental illness and HIV fall under this category. ${ }^{5} 1112$

In the case of HIV, related topics such as sexual behaviour are further marked by anxiety and stigma, ${ }^{13} 14$ and thus pose significant ethical and logistical challenges for data collection. People living with HIV/AIDS (PLHA) can remain hidden and difficult to identify, and also can have the most to fear from volunteering for research, especially if they have not disclosed their status to family members or others in the community. ${ }^{15}$ Recruiting HIV+ participants from a community setting, therefore, presents the double challenge of accessing a marginalised population to explore socially sensitive topics.

Kisesa ward in Mwanza Region, Tanzania, has been the site of an ongoing demographic and HIV cohort study since 1994, administered by the National Institute for Medical Research (NIMR). ${ }^{16}$ It consists of six villages that range from remote rural farming communities to an urban trading centre on the main road from Mwanza town to the Kenyan border. Kisesa was identified as a priority area for the national antiretroviral therapy (ART) programme in acknowledgement of the community's contribution to national HIV data. Regular serological surveys are conducted in temporary village clinics, at which Voluntary Counselling and Testing (VCT) is provided separately. During the 2003-4 round of surveillance, counsellors informed those who chose VCT and tested HIV positive about the planned national ART programme and asked if they wanted to be referred to the regional hospital once treatment became available. Fifty-six persons indicated willingness to be contacted for referral purposes, and their study numbers (but not names) were reported by the VCT counsellors to study managers.

In April 2005, the regional hospital in Bugando began providing ART to clients from Mwanza town and Kisesa ward. An ongoing operations research programme monitors access to and uptake of treatment, working to identify and test community-based interventions to overcome local barriers at each stage along the treatment continuum. One of the first studies comprised qualitative research to assess local perceptions of the newly available medicines, promote treatmentseeking among Kisesa residents and mitigate any emerging challenges faced by the first rural patients referred to the programme. The results of this study have been reported elsewhere, ${ }^{17}$ and here we focus on the approach developed to recruit HIV+ 
community members into the study without inadvertently disclosing their status to others. The method described aimed to optimise PLHA participation in both treatment and research without compromising privacy or exacerbating potential risks of participation.

\section{METHODS}

Although VCT counsellors recorded the study numbers of Kisesa residents willing to undergo ART eligibility tests, this had occurred over a year before therapy become available at the referral hospital, and we did not have any information on whether the 56 potential recruits still wished to be contacted by counsellors, or whether they had disclosed their HIV status to others. Any household visits by NIMR staff would raise questions in the wider community about the targetting of these particular individuals. The presence of the NIMR vehicles would alert neighbours, and even approaching homes on foot would not avoid the possibility that other family members would become suspicious of why their relatives was being recruited into a special study by an institution closely associated with HIV surveillance.

To overcome these ethical considerations, we developed the "seeded focus group" method that combined reaching our target community members with a more comprehensive and proactive attempt to disseminate accurate information on ART. We planned to prospectively follow a pilot group of $12 \mathrm{HIV}+$ community members representing diversity in age, sex and residence across the six villages of Kisesa. A small sample allowed us to gain a rapid "snapshot" of issues faced by the first rural referrals and thus expedite provision of services tailored to local needs, which we continue to monitor and adapt while coping with rising numbers of patients who need support in accessing and sustaining treatment. We began by linking the study numbers of the 56 potential recruits to cohort data providing their sex, age group (under or over 30) and village of residence. We then held focus-group discussions in each village based on the dominant sex and age groups of the potential recruits. This study protocol received ethical approval from the review boards of both NIMR and the London School of Hygiene and Tropical Medicine.

One male and one female potential recruit from the majority age group were chosen at random to become the focus group's "seed," and study numbers of 10-12 other community members from the same village, matched by age group and sex, were randomly selected from the database to construct a list of people invited to the discussion. These lists of study numbers were linked back to a file containing the names and addresses of all the study participants in the community, and provided to project field staff who delivered invitations to all of them to join a focus group addressing current local knowledge and awareness of ART. The study numbers of "seeds" were given to the VCT counsellors, who were able to identify them by referring to their $\log$ books.

\section{RESULTS}

In total, 16 focus-group discussions were organised, including several that did not contain a "seed" to ensure coverage of all study villages even if a targeted participant could not be identified. In the 18-30 "young persons" age group, four discussions were held among women and five among men; for the "adults" aged 31-59, we held three discussions for women and four for men. Four NIMR staff conducted data collection: a male or female social scientist facilitated discussions, assisted by a note-taker, also matched to groups by sex, who could provide translation to the Sukuma language for participants who did not speak Swahili, if necessary. No fieldworker knew who among the invited participants were the "seeded" recruits. Discussions lasted $2-3 \mathrm{~h}$ and used participatory activities including diagrams to map current understanding of ART and story-lines to discuss hypothetical barriers that might be faced by a local resident seeking testing and treatment, and how these might be addressed. Facilitators further briefed participants about the logistics of the new national distribution programme and attempted to dispel any rumours or misconceptions that arose.

Following the discussion, participants were requested to enter a private adjoining room one by one in order to speak to a project counsellor who would answer any personal or sensitive questions that may have been raised, offer appointments for VCT, and pay each participant 2000 Shillings' (about \$2) compensation for their time. The counsellor was always the same nurse who had provided VCT in that village during the serological survey and was therefore the person who had initially given out test results and requested consent for subsequent contact. She knew which of her clients might be participating, and was therefore able to identify the designated recruit and explain the additional research, offer information on how an ART referral could be obtained and request details for acceptable ways to reach the participant in future (usually by mobile telephone or prearranged appointment at the NIMR project office).

Of 12 individuals selected as focus-group "seeds," 10 were located; one had moved from the address provided, and one had died. When approached after the discussion, all 10 volunteered for ART referral and consented to participate in the study on barriers of uptake, although only eight completed research. All subsequent interviews were conducted by the same VCT counsellor, and so the participants' HIV status remained confidential from the rest of the study team as well as other community members.

The focus groups were completed within 2 months, followed by in-depth interviews with "seeds" to monitor their progress through the referral process and, where relevant, initiation of ART. Following this pilot phase, a permanent VCT centre was opened in the central village, and a formal partnership developed with local home-based care organisation Tumaini, which was tasked with conducting an information campaign on testing and ART throughout the ward. Tumaini staff also began to proactively visit local households to promote treatment access, provide information on care for HIV+ family members and support the growing number of individuals on medication. NIMR then passed on the details of the remaining 56 individuals who had initially expressed interest in ART, as well as those of subsequent VCT clients testing positive. As an independent NGO with increasing community presence, Tumaini is able to initiate contact with PLHA without drawing attention to their status as research staff from a demographic and clinical institution would, and offer a more sustainable constellation of support activities. By the end of the first year of operation, 46 persons had been referred for treatment.

\section{DISCUSSION}

We believe this strategy of "seeding" a focus group in order to contact HIV+ community members without inadvertently disclosing their status to others or drawing stigmatising attention strengthened the study in numerous ways and could be adopted in similar settings as part of community-based 
research or initial implementation of ART distribution. Our findings also dovetail with research from developed-country settings on successful strategies for including vulnerable or marginalised populations in health research, as described below.

First, face-to-face contact can build rapport between researchers and community members and assuage potential anxiety toward research activities; in other studies, face-to-face recruitment by a physician has been shown to be one of the most successful methods of enlisting participant support. ${ }^{18}$ In this research, the same VCT counsellor gave HIV+ individuals their results, informed them about future treatment availability and followed up those who were interested by offering a referral to the regional hospital. They demonstrated the project's commitment to confidentiality by approaching them under the guise of the focus group and subsequently made discreet arrangements for further contact. This continuity of care may have contributed to willingness to participate in research.

Second, the focus-group discussions proved useful for eliciting current knowledge and awareness of the introduction of ART in Tanzania and uncovering several misconceptions, misgivings and fears regarding treatment. We were able to gauge levels of community support for ART, which, in a study of HIV vaccine trials proved instrumental in influencing uptake: "... participation, although partially a private decision, occurs within larger sociocultural and community contexts". From a communityparticipation perspective, group discussions provided an opportunity to engage with Kisesa residents and clarify uncertainties, and provided an "entry point" for accurate information and promotion of the referral system. We were also consulting local people about potential barriers to accessing treatment and consequently could initiate measures to mitigate these, such as subsidised travel costs to clinic appointments.

Finally, many other studies have emphasised the importance of including research objectives that explicitly meet the target community's perceived needs and provide meaningful benefits; ${ }^{19}$ indeed, the principles underlying participatory research are based on this. ${ }^{20}$ In our case, the people of Kisesa have contributed to over 10 years of longitudinal demographic, behavioural and serological studies. By fast-tracking community provision of ART, developing activities to facilitate access for rural communities and making a concerted effort to locate and contact individuals who had tested HIV+ to ensure they were aware of and took advantage of newly available treatment, we demonstrated that our research could directly benefit target populations, and that we were able to "give something back." The "seeded" focus groups contributed to disseminating this message to small groups and some of the most vulnerable individuals at the same time.

The ease of using this method in Kisesa ward was considerably aided by the well-established research infrastructure available at NIMR and the long-term relationship developed between researchers and the local community. Thus, when residents were invited to group discussions on ART, over twothirds attended, with refusals generally attributed to time constraints rather than reluctance to participate. Local leaders offered village centres (a small compound of several thatched huts) for participatory activities, ensuring privacy during discussions and individual meetings with counsellors. This method may therefore be best suited in settings where services for PLHA are initiated against a backdrop of sustained trust and communication between the community and health researchers and providers. Furthermore, we were lucky to have continuity of staff so that "seeds" could be approached by the VCT counsellor who had conducted their test over a year previously; we feel, however, that most participants would have been amenable to a private consultation with a new VCT counselling nurse, as there have since been changes in NIMR personnel (as well as hand-over of daily interactions with households to the home-based care organisation), and these do not appear to have affected our ability to recruit HIV+ individuals into research monitoring ART referral and compliance.

\section{CONCLUSION}

Providing detailed explanations of research aims and procedures, consulting with community stakeholders and opinion leaders, and creating appropriate links to other relevant services or organisations have been identified as successful strategies for reaching out to vulnerable communities and ensuring they are both represented in and benefited by research findings. ${ }^{21-23}$ Most previous work has been conducted in developed-country settings, and few practical steps have been described for making the first contact with community-based PLHA without risking disclosing their status. The "seeded" focus group is a very straightforward and easily arranged method of recruiting HIV+ people for research or service delivery within a wider context of engaging with local perceptions and priorities.

Acknowledgements: We wish to acknowledge the dedication and efforts of the project counsellors, G Maiseli and R Manyalla, who conducted all fieldwork throughout this study.

Funding: Andrew W Mellon Foundation, Global Fund for AIDS, Tuberculosis and Malaria, and UK Department for International Development.

Competing interests: None.

Ethics approval: Ethics approval was provided by the review boards of National Institute for Medical Research and the London School of Hygiene and Tropical Medicine.

Patient consent: Obtained.

\section{REFERENCES}

1. McCabe MS, Varricchio CG, Padberg RM. Efforts to recruit the economically disadvantaged to national clinical trials. Semin Oncol Nurs 1994;10:123-9.

2. Hessol NA, Schneider M, Greenblatt RM, et al. Retention of women enrolled in a prospective study of human immunodeficiency virus infection: impact of race, unstable housing, and use of human immunodeficiency virus therapy. Am J Epidemiol 2001;154:563-73.

3. Newman PA, Duan N, Roberts KJ, et al. HIV vaccine trial participation among ethnic minority communities: barriers, motivators, and implications for recruitment. J Acquir Immune Defic Syndr 2006;41:210-17.

4. Luisa Zuniga M, Blanco E, Martinez $P$, et al. Perceptions of barriers and facilitators to participation in clinical trials in HIV-positive Latinas: a pilot study. J Women's Health 2007;16:1322-30.

5. Owen S. The practical, methodological and ethical dilemmas of conducting focus groups with vulnerable clients. J Adv Nurs 2001;36:652-8.

6. Brown DR, Topcu M. Willingness to participate in clinical treatment research among older African Americans and Whites. Gerontologist 2003;43:62-72.

7. Nguyen OK, Dore GJ, Kaldor JM, et al. Recruitment and follow-up of injecting drug users in the setting of early hepatitis $\mathrm{C}$ treatment: insights from the ATAHC study. Int J Drug Pol 2007;18:447-51.

8. World Health Organization. Accelerating the global effort for HIV vaccine research Geneva: WHO, 2006.

9. Wassenaar DR, Barsdorf NW. The ethical involvement of women in HIV vaccine trials in Africa. Women Health 2007;45:37-50.

10. Kavanaugh K, Moro TT, Savage T, et al. Enacting a theory of caring to recruit and retain vulnerable participants for sensitive research. Res Nurs Health 2006;29:24452.

11. Kreiger $\mathbf{N}$, Ashbury F, Cotterchio $\mathrm{M}$, et al. A qualitative study of subject recruitment for familial cancer research. Ann Epidemiol 2001;11:219-24.

12. Witte SS, El-Bassel N, Gilbert L, et al. Recruitment of minority women and their main sexual partners in an HIV/STI prevention trial. J Women's Health 2004;13:1137-47.

13. Parker R, Aggleton P. HIV and AIDS-related stigma and discrimination: a conceptual framework and implications for action. Soc Sci Med 2003;57:13-24.

14. Busza JR. Promoting the positive: responses to stigma and discrimination in Southeast Asia. AIDS Care 2001;13:441-56.

15. Strauss RP, Sengupta $S$, Kegeles $S$, et al. Willingness to volunteer in future preventive HIV vaccine trials: issues and perspectives from three US communities. J Acquir Immune Defic Syndr 2001;26:63-71. 
16. Mwaluko G, Urassa M, Isingo R, et al. Trends in HIV and sexual behaviour in a longitudinal study in a rural population in Tanzania, 1994-2000. AIDS 2003;17:2645-51.

17. Mshana GH, Wamoyi J, Busza J, et al. Barriers to accessing antiretroviral therapy in Kisesa, Tanzania: a qualitative study of early rural referrals to the national program. AIDS Patient Care STDS 2006;20:649-57.

18. Loftin WA, Barnett SK, Bunn PS, et al. Recruitment and retention of rural African Americans in diabetes research: lessons learned. Diabetes Educator 2005;31:251-9.

19. McCallum TJ, Arlien CR. Enhancing the matching model of recruitment through focus groups. Aging Mental Health 2006;10:312-18.
20. Pretty JN, Gujit I, Thompson J, et al. Participatory learning and action: a trainer's guide. London: IIED, 1995.

21. Dageid W, Ducker $F$. The process of evaluating a capacity-building support initiative for HIV positive South Africans. Eval Prog Plann 2007;30:381-91.

22. Vallely A, Shagi $\mathrm{C}$, Kasindi $\mathrm{S}$, et al. The benefits of participatory methodologies to develop effective community dialogue in the context of a microbicide trial feasibility study in Mwanza, Tanzania. BMC Publ Health 2007;7:133.

23. Aubel J, Samba-Ndure K. Lessons on sustainability for community health projects. World Health Forum 1996;17:52-7. 


\section{STl The "seeded" focus group: a strategy to recruit HIV+ community members into treatment research}

J Busza, B Zaba and M Urassa

Sex Transm Infect 2009 85: 212-215 originally published online August 6, 2008

doi: 10.1136/sti.2008.029835

Updated information and services can be found at:

http://sti.bmj.com/content/85/3/212

These include:

References This article cites 21 articles, 3 of which you can access for free at: http://sti.bmj.com/content/85/3/212\#BIBL

Email alerting Receive free email alerts when new articles cite this article. Sign up in the service box at the top right corner of the online article.

Topic Articles on similar topics can be found in the following collections

Collections

Drugs: infectious diseases (3156)

HIV / AIDS (2489)

HIV infections (2489)

HIV/AIDS (2489)

Confidentiality (229)

Epidemiologic studies (751)

\section{Notes}

To request permissions go to:

http://group.bmj.com/group/rights-licensing/permissions

To order reprints go to:

http://journals.bmj.com/cgi/reprintform

To subscribe to BMJ go to:

http://group.bmj.com/subscribe/ 